\title{
Erratum to: Intelligent Tutoring Math Platform Accessible for Visually Impaired People
}

\author{
Piotr Brzoza and Michał Maćkowski \\ Silesian University of Technology, Gliwice, Poland \\ \{piotr.brzoza, michal.mackowski\}@polsl.pl
}

\section{Erratum to: \\ Chapter 81 in: K. Miesenberger et al. (Eds.) \\ Computers Helping People with Special Needs, DOI: 10.1007/978-3-319-08596-8 81}

In the original version the following reference was missing:

Brzoza, P., Łobos, E., Macura, J., Sikora, B., Żabka, M.: ForMath - Intelligent Tutoring System in Mathematics, 4th International Conference on Computer Supported Education (CSEDU 2012), pp. 118-122, Porto, Portugal, 16-18 April (2012) 